\title{
Measuring perceived benefit and disease-related burden in young cancer survivors: validation of the Benefit and Burden Scale for Children (BBSC) in the Netherlands
}

\author{
Heleen Maurice-Stam • Anna Broek • Annemarie M. M. Kolk • \\ Jantien M. J. Vrijmoet-Wiersma • Esther Meijer-van den Bergh • \\ Elisabeth M. van Dijk • Sean Phipps • Martha A. Grootenhuis
}

Received: 15 February 2011 / Accepted: 30 May 2011 /Published online: 11 June 2011

(C) The Author(s) 2011. This article is published with open access at Springerlink.com

\begin{abstract}
Purpose Perceiving favourable changes from one's illness may go hand in hand with experiencing harmful psychosocial effects. Each of these constructs should be considered
\end{abstract}

Heleen Maurice-Stam and Anna Broek contributed equally to this manuscript.

Annemarie M.M. Kolk is deceased.

H. Maurice-Stam · A. Broek · M. A. Grootenhuis

Paediatric Psychosocial Department,

Emma Children's Hospital Academic Medical Centre,

Amsterdam, The Netherlands

A. M. M. Kolk

Department of Clinical Psychology, University of Amsterdam, Amsterdam, The Netherlands

J. M. J. Vrijmoet-Wiersma

Paediatric Department, Leiden University Medical Centre,

Leiden, The Netherlands

E. Meijer-van den Bergh

Medical Psychology, Radboud University Medical Centre,

Nijmegen, The Netherlands

E. M. van Dijk

Medical Psychology, VU University Medical Centre,

Amsterdam, The Netherlands

\section{S. Phipps}

Department of Behavioural Medicine,

St. Jude Children's Research Hospital,

Memphis, TN, USA

H. Maurice-Stam $(\triangle)$

Paediatric Psychosocial Department,

EKZ Academic Medical Centre,

A3-241 Meibergdreef 9,

NL-1105 AZ Amsterdam, The Netherlands

e-mail: h.stam@amc.uva.nl when examining children's levels of psychological adjustment following stressful life events. A paediatric instrument that accounts for both positive and negative impact of stressful events has not been investigated in the Netherlands before. The aim of the study was to investigate psychometric properties of the Dutch version of the Benefit and Burden Scale for Children (BBSC), a 20-item questionnaire that intends to measure potential benefit and burden of illness in children.

Methods Dutch paediatric survivors of childhood cancer aged $8-18 \quad(N=77)$ completed the BBSC and other psychological questionnaires: Pediatric Quality of Life Inventory (health-related quality of life), State-Trait Anxiety Inventory for Children (anxiety), Children's Revised Impact of Event Scale (posttraumatic stress) and Strengths and Difficulties Questionnaire (behavioural functioning). Reliability and validity were evaluated.

Results Internal consistency (Cronbach's alpha, benefit 0.84 , burden 0.72 ), test-retest reliability (benefit $r=0.74$, burden $r=0.78$ ) and homogeneity (mean inter-item correlation, benefit $r=0.34$, burden $r=0.22$ ) were satisfactory. Burden was associated with HRQoL (-), anxiety $(+)$, posttraumatic stress symptoms $(+)$ and behavioural problems. Benefit did not correlate with the psychological outcomes.

Conclusions The Dutch version of the BBSC shows promising psychometric properties. Perceived benefit and disease-related burden are distinct constructs; both should be considered when examining children's psychological adjustment to potentially traumatic experiences. The BBSC may be useful as monitoring and screening instrument.

Keywords Pediatric oncology. Survivor. Childhood cancer- Instrument development - Quality of life .

Psychosocial 


$\begin{array}{ll}\text { Abbreviations } \\ \text { BBSC } & \text { Benefit and Burden Scale for Children } \\ \text { CNS } & \text { Central nervous system } \\ \text { CRIES } & \text { Children's Revised Impact of Event Scale } \\ \text { HRQoL } & \text { Health-related quality of life } \\ \text { M } & \text { Mean } \\ \text { PedsQL } & \text { Pediatric Quality of Life Inventory } \\ \text { SD } & \text { Standard deviation } \\ \text { SDQ } & \text { Strengths and Difficulties Questionnaire } \\ \text { SES } & \text { Socioeconomic status } \\ \text { STAI-C } & \text { State-Trait Inventory for Children }\end{array}$

\section{Introduction}

Since more than $70 \%$ of children with cancer in Europe manage to survive [11], the significance of monitoring the effects of the disease and treatment in a later developmental stage has gained recognition. The literature on the long-term psychosocial consequences of childhood cancer has yielded contradictory results. In many studies, overall adjustment has been found to be near normal levels [17]. Many survivors seem to cope well with the cancer experience and several young adult survivors report positive effects, for example with regard to resiliency [22] or posttraumatic growth [2]. However, the results of other studies suggest that survivors suffer more from depression, anxiety and posttraumatic stress symptoms than the general population $[8,16]$. Furthermore, specific areas are adversely affected in long-term survivors, for example body image and identity [10] and peer relations $[14,18]$. Disease-related worries were also reported [9]. These findings suggest that the negative impact of growing up with cancer (i.e. burden) can go along with positive impact (i.e. benefit) probably even in the same survivor. The construct of benefit finding offers explanation for positive adjustment in children. It may be conceptualized as adaptive beliefs about the consequences of adversity [20] reflected by transformations in a person's self-perceptions, the self in relation to others and changes in life philosophy [19].

Phipps and colleagues developed the Benefit and Burden Scale for Children (BBSC) [5, 15], as far as we know, the first questionnaire that addresses both constructs in children. The aim of the present study was to examine the psychometric properties of the Dutch version of the BBSC in a sample of paediatric survivors of childhood cancer. It was hypothesized that the Dutch version of the BBSC would show good psychometric properties, similar to the original American version [5, 15]. Firstly, good internal consistency was expected. Secondly, with respect to the construct validity of the BBSC, we hypothesized that perceived a burden was positively associated with anxiety and posttraumatic stress symptoms. Benefit finding was expected not to associate with these psychological outcomes. Thirdly, survivors' benefit and burden were expected not to differ as a function of sociodemographic or medical characteristics with the exception of current age and age at diagnosis. Older survivors (at diagnosis) were hypothesized to have a greater likelihood of finding benefit than younger survivors. Going beyond Phipps [15] and Currier et al. [5], we also studied homogeneity, testretest reliability and some additional psychological outcomes for construct validity; burden was hypothesized to be negatively related to health-related quality of life (HRQoL) and positively to behavioural problems.

\section{Methods}

Participants and procedure

Children who had received cancer treatment in the Emma Children's Hospital AMC, the VU University Hospital, the Radboud University Nijmegen Medical Centre or the Leiden University Medical Centre were selected (December 2008 to February 2009) for this study. Inclusion criteria were: aged between 8 and 18 and end of treatment from 6 months to 3 years before inclusion. Exclusion criteria were: participating in another study, recent relapse and insufficient understanding of the Dutch language.

Children and their parents were sent an invitation to participate, an informed consent form, a booklet with questionnaires to be completed by the child and a form addressing sociodemographic and medical details to be completed by the parent. After a month, non-responders were reminded by telephone. Two weeks after completion of the questionnaires, the BBSC was sent a second time in order to assess test-retest reliability.

A total of 77 out of 126 invited children (61\%) participated in the study. Four children did not match the criterion of the timeframe since the end of treatment but were still included because this criterion was not based on theoretical grounds. Age and sex of the participants did not differ $(p<0.05)$ from those of the non-respondents; mean age 13.8 versus 13.7 years, $52 \%$ versus $52 \%$ boys. The characteristics of the 77 participants were: age at diagnosis, mean $(M)=10.2$ years ( $\mathrm{SD}=3.6)$; time since diagnosis $M=3.2(\mathrm{SD}=1.4)$; times since the end of treatment $M=1.8$ (SD=0.9); $64.9 \%$ leukaemia or lymphoma, $27.3 \%$ solid tumour, $7.8 \%$ CNS cancer; $98.7 \%$ chemotherapy, $58.4 \%$ surgery, $36.4 \%$ radiotherapy. Some $14.3 \%$ of the children were treated for a relapse of the cancer.

A total of 69 out of the 77 respondents $(89.6 \%)$ completed the retest of the BBSC. The age and sex of the children participating in the retest did not differ (at $p<0.05$ ) from that of the children who only completed the first questionnaire; mean age 13.6 versus 15.4 years; 52\% versus $44 \%$ boys. 


\section{Instruments}

Benefit finding and disease-related burden were measured with the BBSC, a 20-item self-report instrument for children aged 7 years and older developed by Phipps and Currier [5, 15]. The items describe potential benefit (ten items) or burden (ten items) of illness that can be answered on a five-point Likert scale ranging from 1 'not at all true for me' to 5 'very true for me'. The items include affect, relationships with peers and family relationships. Higher scores indicate higher benefit and burden (scale range 10-50). The BBSC has shown to be reliable and valid in an American childhood cancer population with benefit and burden as independent constructs [5]. The Dutch version of the BBSC was established by a forwardbackward translation. The backward translation was crosschecked for inconsistencies by the author of the original BBSC [5, 15].

HRQoL was assessed with the validated Dutch version of the Pediatric Quality of Life Inventory (PedsQL) Generic Core Scales [3, 21]. This validated questionnaire assesses HRQoL in children and adolescents in four domains: physical, emotional, social, and school functioning. Summing the scores from all domains generates a total HRQoL score. Summing the scores of emotional, social and school functioning leads to the scale psychosocial functioning. Higher scores indicate better HRQoL.

Anxiety was estimated with the validated Dutch version of the State-Trait Anxiety Inventory for Children (STAI-C) [1]. The 'trait anxiety' version was used. Higher scores indicate higher levels of anxiety in a threatening situation.

Posttraumatic stress symptoms were measured with the Dutch version of the Childrens' Revised Impact of Event Scale (CRIES) [13], which is a 13-item version of the Impact of Event Scale [7]. In the present study, children were asked to keep their experience with cancer in mind when answering the questions about a traumatic event. The CRIES consists of three subscales: intrusion (four items), avoidance (four items) and arousal (five items). The items are scored on a four-point scale: 0 'not at all', 1 'rarely', 3 'sometimes' and 5 'often'. When the sum of the scores on the subscales intrusion and avoidance equals 17 or more, this indicates that there are serious posttraumatic stress symptoms and that the child is likely to meet the criteria for a diagnosis of PTSD.

Behavioural functioning was assessed with four scales of the validated Dutch version of the Strengths and Difficulties Questionnaire for children aged 1116 years (SDQ) [6, 12]: emotional symptoms, prosocial behaviour, total difficulties and impact of difficulties.

Medical and sociodemographic characteristics include diagnosis, treatment, time since diagnosis, time since the end of treatment, age at diagnosis, age at study, gender, ethnicity and socioeconomic status (i.e. work status of parents, education of parents). This information was obtained from the parents of the survivors and from the survivors' medical records.

\section{Statistical analyses}

One-way ANOVA and $\chi^{2}$ tests were conducted to compare participants and non-participants with regard to child characteristics $(\alpha=5 \%)$.

Internal consistency and homogeneity of the BBSC were evaluated by using the following norms: Cronbach's alpha above 0.70 , mean inter-item correlations 0.20 to 0.40 and item-total correlations above 0.20 . Test-retest reliability was evaluated by assessing Pearson's correlation coefficients to be above 0.70 .

Validity was investigated by assessing Pearson's correlation coefficients of benefit and burden with the other psychological outcomes. The correlations of medical and sociodemographic variables with benefit and burden were analysed using Pearson's correlation coefficients or oneway ANOVA for dichotomous or nominal sociodemographic and medical variables.

The Statistical Package for Social Sciences version 16.0 was used for all analyses. A significance level of 0.05 was used. However, a Bonferroni correction was applied for the correlation analyses of benefit and burden with the other psychological outcomes resulting in a significance level of $0.003(0.05 / 15)$. We considered correlation coefficients of 0.1 as small, 0.3 as medium and 0.5 as large, according to Cohen [4].

\section{Results}

\section{Reliability}

Benefit and burden demonstrated good internal consistency ( $\alpha=0.84$ and $\alpha=0.72$, respectively). Furthermore, testretest reliability, measured with a mean interval of 21 days, was satisfactory: Pearson's correlation coefficient 0.74 for benefit and 0.78 for burden (Table 1 ).

Homogeneity indexes were satisfactory: mean inter-item correlations 0.34 for benefit and 0.22 for burden and itemtotal correlations 0.34 to 0.71 for benefit. With a range from 0.08 to 0.50 the item-total correlations of burden were less satisfying caused by item 18 ('I worry that I will bring other people down or upset them'). When this item was deleted, the item-total correlations were 0.35 to 0.50 .

\section{Construct validity}

Burden correlated strongly $(r \geq 0.5 ; p<0.001)$ with 11 out of 15 psychological outcomes (Table 2). Higher levels of 
Table 1 Characteristics of the Dutch versus American BBSC a Score range 1 'not at all true' to 5 'very true'

${ }^{\mathrm{b}}$ After deletion of item 18 $* p<0.01, * * p<0.001$, difference between Dutch and American score

\begin{tabular}{|c|c|c|c|c|}
\hline & \multicolumn{2}{|l|}{ Dutch } & \multicolumn{2}{|l|}{ American } \\
\hline & Benefit & Burden & Benefit & Burden \\
\hline \multicolumn{5}{|l|}{ Descriptives } \\
\hline$N$ & 77 & 77 & 78 & 78 \\
\hline Mean scale score & $32.0 * *$ & $16.2 * *$ & 37.0 & 21.0 \\
\hline SD & 8.4 & 5.3 & 8.6 & 7.7 \\
\hline Range & $11-49$ & $10-34$ & $17-50$ & $10-45$ \\
\hline Mean item score ${ }^{a}$ & 3.2 & 1.6 & 3.7 & 2.1 \\
\hline \multicolumn{5}{|l|}{ Reliability } \\
\hline Cronbach's $\alpha$ & 0.84 & 0.72 & 0.85 & 0.80 \\
\hline Test-retest correlation, $r$ & $0.74 *$ & $0.78^{*}$ & - & - \\
\hline Mean inter-item correlation, $r$ & 0.34 & 0.22 & - & - \\
\hline \multirow[t]{2}{*}{ Item-total correlation, $r$} & $0.34-0.71$ & $0.08-0.50$ & $0.34-0.60$ & - \\
\hline & & $0.35-0.50^{\mathrm{b}}$ & & \\
\hline
\end{tabular}

burden were associated with lower HRQoL, higher levels of anxiety, more posttraumatic stress symptoms and more behavioural problems. Benefit did not correlate with any psychological outcome.

Table 2 Pearson's correlations of benefit and burden with other psychological measures

\begin{tabular}{llll}
\hline & & $\begin{array}{l}\text { Benefit } \\
r\end{array}$ & $\begin{array}{l}\text { Burden } \\
r\end{array}$ \\
\hline HRQoL (PedsQL) & & & \\
Physical functioning & 75 & -0.18 & $-0.62^{* *}$ \\
Emotional functioning & 75 & -0.02 & $-0.57^{* *}$ \\
Social functioning & 75 & -0.05 & $-0.63^{* *}$ \\
School functioning & 75 & -0.14 & $-0.47^{* *}$ \\
Psychosocial functioning & 75 & -0.09 & $-0.68^{* *}$ \\
Total HRQoL & 75 & -0.15 & $-0.73^{* *}$ \\
Anxiety (STAI-C) & 77 & 0.11 & $0.60^{* *}$ \\
PTSS (CRIES) & & & \\
Intrusion & 77 & 0.08 & $0.52^{* *}$ \\
Avoidance & 77 & 0.14 & $0.38^{*}$ \\
Arousal & 77 & -0.03 & $0.53^{* *}$ \\
Indication of PTSD & 77 & 0.13 & $0.49^{* *}$ \\
Behavioural difficulties (SDQ) & & & \\
Emotional symptoms & 59 & -0.01 & $0.54^{* *}$ \\
Prosocial behaviour & 59 & 0.15 & -0.17 \\
Total difficulties & 59 & -0.05 & $0.55^{* *}$ \\
Impact of difficulties & 29 & 0.25 & $0.56^{*}$ \\
\hline
\end{tabular}

$H R Q o L$ health-related quality of life, PTSS posttraumatic stress symptoms, CRIES Children's Revised Impact of Event Scale, PTSD posttraumatic stress disorder, $S D Q$ strengths and difficulties questionnaire, Peds $Q L$ pediatric quality of life inventory STAI-C State-Trait Anxiety Inventory for Children

${ }^{*} p<0.003, * * p<0.001$
BBSC as a function of medical and sociodemographic characteristics

The older age at study and at diagnosis, the higher benefit the child reported; $r=0.27, p<0.05$ and $r=0.31, p<0.01$ respectively. Subsequently, the more time elapsed since the end of treatment, the lower benefit and burden were experienced $(p<$ $0.05)$ : $<1$ year after treatment benefit $M=36.2(\mathrm{SD}=6.6)$ and burden $M=18.4(\mathrm{SD}=5.6)$ versus $\geq 1$ year after treatment benefit $M=30.7$ ( $\mathrm{SD}=8.5$ ) and burden $M=15.5$ (SD=5.1). In addition, children with a brain tumour reported higher levels of burden than children with a different cancer diagnosis: $M=21.5$ ( $\mathrm{SD}=6.7$ ) versus $M=15.7$ ( $\mathrm{SD}=4.9) ; p<0.05$. The children's benefit and burden scores did not differ as a function of gender, ethnicity, socioeconomic status (parental education and work status), treatment, relapse and time since diagnosis.

\section{Discussion}

The shift from focusing exclusively on the negative aspects of highly stressful events to focusing on ways in which these events promote positive life changes is a relatively new one in paediatrics. It is noteworthy that the survivors in the present study reported levels of benefit finding that were on average twice the level of disease-related burden.

A paediatric instrument that accounts for both positive and negative impact of stressful events has not been investigated in the Netherlands before. The BBSC demonstrated satisfactory internal consistency, test-retest reliability and homogeneity, though the item-total correlations of the Burden scale would rise when item 18 ('I worry that I will bring other people down or upset them') would be removed.

The results of our study support the construct validity of the Dutch version of the BBSC. In line with the American version 
of the BBSC [5], disease-related burden was strongly associated with almost all psychological outcomes, while benefit finding was not. These results suggest that the level of perceived burden is possibly a better predictor of distress than the amount of benefit the child experiences. In addition, it indicates that benefit and burden are distinct constructs representing different aspects of child's response to a potentially traumatic experience. Positive experiences do not simply imply an absence of distress or harmful effects. In line with Currier et al. [5], the children's benefit and burden scores did hardly differ as a function of medical and sociodemographic characteristics.

The psychometric results are promising, though the Dutch version of the BBSC requires further psychometric evaluation in a larger sample, including the assessment of its dimensionality and factor invariance. The present study focused on a rather small sample of children who survived cancer, which limits the ways the conclusions can be generalized to other populations of children who have experienced highly stressful events.

Our findings indicate that patients who perceive negative implications of the disease and treatment have a less favourable psychosocial adjustment. Longitudinal research is needed to prove causality and to study the mechanism behind, so that interventions could be developed. Improving benefit finding could be a part of intervention development. Furthermore, it should be investigated whether the BBSC could be used with survivors older than 18 years of age.

The BBSC could contribute to patient care. Considering the rather strong association of disease-related burden with HRQoL, anxiety, PTSS and behavioural difficulties, it seems the BBSC will be able to make a useful contribution as a monitoring or a screening instrument in the long-term follow-up of childhood cancer survivors. The feasibility of the BBSC seems promising because of the short length and the positive nature of many items.

Acknowledgements We would like to thank Eefje Verhoof, AnneSophie Darlington and Madelon Bronner for their contribution to the translation of the BBSC.

Conflict of interest This study was not funded. The authors have full control of all primary data and agree to allow the journal to review the data if requested.

Open Access This article is distributed under the terms of the Creative Commons Attribution Noncommercial License which permits any noncommercial use, distribution, and reproduction in any medium, provided the original author(s) and source are credited.

\section{References}

1. Bakker FC, van Wieringen PCW, van der Ploeg HM, Spielberger CD (1989) Handleiding bij de Zelf-beoordelings Vragenlijst voor Kinderen (ZBV-K). Een Nederlandse bewerking van de State-Trait-Anxiety Inventory for Children (STAI-C) van Spielberger et al. [Manual of the Dutch version of the STAI-C]. Swets Test Services, Lisse
2. Barakat LP, Alderfer MA, Kazak AE (2006) Posttraumatic growth in adolescent survivors of cancer and their mothers and fathers. $J$ Pediatr Psychol 31:413-419

3. Bastiaansen D, Koot HM, Bongers IL, Varni JW, Verhulst FC (2004) Measuring quality of life in children referred for psychiatric problems: psychometric properties of the PedsQL 4.0 generic core scales. Qual Life Res 13:489-495

4. Cohen J (1988) Statistical power analysis for the behavioral sciences. Academy Press, New York

5. Currier JM, Hermes S, Phipps S (2009) Brief report: children's response to serious illness: perceptions of benefit and burden in a pediatric cancer population. J Pediatr Psychol 34:1129-1134

6. Goodman R, Meltzer H, Bailey V (1998) The strengths and difficulties questionnaire: a pilot study on the validity of the selfreport version. Eur Child Adolesc Psychiatry 7:125-130

7. Horowitz MJ, Wilner N, Alvarez W (1979) Impact of event scale: a measure of subjective stress. Psychosom Med 41:209-218

8. Hudson MM, Mertens AC, Yasui Y, Hobbie W, Chen H, Gurney JG, Yeazel M, Recklitis CJ, Marina N, Robison LR, Oeffinger KC (2003) Health status of adult long-term survivors of childhood cancer: a report from the childhood cancer survivor study. JAMA 290:1583-1592

9. Langeveld NE, Grootenhuis MA, Voûte PA, de Haan RJ, van den Bos C (2004) Quality of life, self-esteem and worries in young adult survivors of childhood cancer. Psychooncology 13:867-881

10. Madan-Swain A, Brown RT, Foster MA, Vega R, Byars K, Rodenberg W, Bell B, Lambert R (2000) Identity in adolescent survivors of childhood cancer. J Pediatr Psychol 25:105-115

11. Magnani C, Pastore G, Coebergh J, Viscomi S, Spix C, SteliarovaFoucher E (2006) Trends in survival after childhood cancer in Europe, 1978-1997: report from the Automated Childhood Cancer Information system project (AGGIS). Eur J Cancer 42:1981-2005

12. Muris P, Meesters C, van den Berg F (2003) The Strengths and Difficulties Questionnaire (SDQ) - further evidence for its reliability and validity in a community sample of Dutch children and adolescents. Eur Child Adolesc Psychiatry 12:1-8

13. Olff M (2005) Herziene Kinder Schokverwerkingslijst [Dutch version of the children's revised impact of event scale]. Academisch Medisch Centrum, Amsterdam

14. Pendley JS, Dahlquist LM, Dreyer Z (1997) Body image and psychosocial adjustment in adolescent cancer survivors. J Pediatr Psychol 22:29-43

15. Phipps S, Long AM, Ogden J (2007) Benefit finding scale for children: preliminary findings from a childhood cancer population. J Pediatr Psychol 32:1264-1271

16. Schwartz L, Drotar D (2006) Posttraumatic stress and related impairment in survivors of childhood cancer in early adulthood compared to healthy peers. J Pediatr Psychol 31:356-366

17. Stam H, Grootenhuis MA, Last BF (2001) Social and emotional adjustment in young survivors of childhood cancer (review). Support Care Cancer 9:489-513

18. Stam H, Grootenhuis MA, Last BF (2005) The course of life of survivors of childhood cancer. Psychooncology 14:227-238

19. Tedeschi RG, Park CL, Calhoun LG (1998) Posttraumatic growth: conceptual issues. In: Tedeschi RG, Park CL, Calhoun LG (eds) Posttraumatic growth: positive changes in the aftermatch of crisis. Erlbaum, New Jersey, pp 1-22

20. Tennen H, Affleck G (1997) Social comparison as a coping process: a critical review and application to chronic pain disorders. In: Buunk BP, Gibbons FX (eds) Health, coping, and well-being: perspectives from social comparions theory. Erlbaum, Mahwah, pp 263-298

21. Varni JW, Limbers CA, Burwinkle TM (2007) How young can children reliably and validly self-report their health-related quality of life?: an analysis of 8,591 children across age subgroups with the PedsQL 4.0 Generic Core Scales. Health Qual Life Outcomes 5:1

22. Zebrack BJ, Chesler MA (2002) Quality of life in childhood cancer survivors. Psychooncology 11:132-141 